\title{
DISCUSSION ON THE CORRECTION OF ERRORS OF REFRACTION*
}

BY

\author{
ERnest Clarke, M.D., F.R.C.S., \\ LONDON.
}

A DISCUSSION on this subject naturally divides itself into two main parts :

(1) What errors should be corrected?

(2) How should they be corrected ?

We cannot deal with number two, which is treatment, until we have settled number one.

There are perhaps few, if any, living who belong to the "old school," which taught that no astigmatism under $1 \mathrm{D}$. need be corrected ; that cycloplegics were hardly ever necessary in refraction work; that refractions were almost best left to the optician; and that the work was rather undignified.

But still a large number of ophthalmologists in this country have not yet grasped the immense importance of careful refraction work, and if this Congress by a majority settles once for all the proper answer to the above questions, it will confer a great benefit on the profession, and cause us heartily to congratulate the Council who have chosen the subject.

We will now discuss the first question, which is, "What errors of refraction should be corrected?"-or, better, "When should errors of refraction be corrected?"

Nature starts èvery living organism with a "push," an amount of nerve energy or "Vril," which is calculated to enable the organism to reach maturity, and then reproduce its species, at which point Nature has finished with it. This act of reproduction often in the lower organisms uses up all the remaining nerve energy. The spider lays her eggs and dies, the flower seeds and dies; but in man there is a higher purpose intended, and consequently it behoves us to prevent as much waste of this "Vril" as possible. We do not know if lost energy can ever be replaced in the true sense, but we do know that its waste can be prevented. Crile, amongst others, has shown the different channels by which waste may occur, but it was Gould who pointed out years ago that one of the commonest, and often perhaps the least suspected, source of waste was eyestrain.

We cannot praise too highly the teachings of this great pioneer, who with Donders, will always stand as an enormous benefactor of mankind. Labelled at first as a lunatic, derided and lampooned, accepted only by a very few (I am proud to have been amongst that number from the first), he is at last coming into his own.

* An opening address, introducing a discussion upon Errors of Refraction, at the Oxford Ophthalmological Congress, July, 1917. 
Now, what did Gould principally point out? That the individual whose vision was above suspicion might be the first to be suspected.

Gould, in his "Biographic Clinics," refers, amongst other highly interesting points, to the possibility that such men as Darwin and Huxley died before their time because they had wasted their nerve energy through the eyes. Darwin obtained relief from his dyspepsia by lying down and closing his eyes, and Huxley took long walks by night over the moors. Both of them had small errors of refraction that were not suspected to exist, and obtained relief by not using their eyes.

It will be interesting to hear from those of you who have studied the subject, what your experience is with regard to the existence of absolutely normal refraction.

I recently tabulated the results of 5,000 refractions, and I found only nine emmetropic, and probably with a little more care I could have eliminated these nine!

Assuming that no eye is absolutely normal, i.e., emmetropic, and that a minute error is always present, and knowing that the craving for distinct and single vision is ever present, impulses passing from the brain to the ciliary muscles to procure distinct vision, and to the external muscles of the eye for parallelism; a certain amount of nerve energy must be used up in the daily wakeful life of all individuals. This, when it exists alone, as in the healthy individual leading more or less an outdoor life, is negligible, as it forms such a small fraction of the whole available amount; but when we come to those who have lost, perhaps half, or even more of their life energy, this drain is at once apparent, and Dr. Harwood, at the King George Hospital, has shown that the bandaging up of one or both eyes produces an immediate improvement in these patients, and, following this line of treatment, the exact correction of the ocular error with glasses has the same beneficial effect.

It may be asked, if emmetropia and parallelism of the eyes are so rare, why should not everyone wear glasses? As the drain is so insidious, perhaps, theoretically, they should, but the annoyance caused to the individual by this treatment would negative the good, and the remedy would be worse than the disease; but, when the error leads to nerve waste which is too large a proportion of the available energy, then it ought to be corrected.

Let me take a simple example: We find a child of twelve years of age with $3 \mathrm{D}$. of simple hypermetropia in each eye, there is 11 or $12 \mathrm{D}$. of accommodative power, and there is no squint. He will not harm much if we prescribe no glasses; but take him at twenty-five years old with the same error, his accommodative power is then reduced to $7 \mathrm{D}$.; the error then is almost one-half of his total power, whereas at twelve, it was only a quarter. We know that at twentyfive he will have distinct manifestations of eyestrain and the error 
must be corrected. So much for the individual at different times. Now take the individual at about the same time and under different conditions. A young man with a small amount of astigmatism or anisometropia, or both, lives an outdoor life, hunting, golfing, etc., no symptoms and no necessity to wear glasses. The same man a few months later returns from the war having suffered from wounds and shell-shock. He will have lost a very large amount of nerve energy, and the waste through eyestrain - which originally was negligible-must be arrested, because it forms such a much larger proportion of the whole.

We have seen in this war the enormous benefit that can be obtained by correcting even $0 \cdot 12 \mathrm{D}$. of astigmatism, or 0.25 of anisometropia in "war neurasthenics" and those suffering from shell-shock. It is well known that shock of any kind leads to loss of nerve energy. Witness the well-known saying," that when an individual has been in an accident, collision, or undergone a serious operation, "he will never be the same man again." "Virtue" has left him never to return. When the shock is combined with loss of blood, previous fatigue and anxiety, we can easily see that it would be difficult to get a worse example. Rest is the treatment indicated in these cases, and yet, as soon as he is able to do so, the soldier starts reading, reading more, perhaps, than he ever did before, and this very rest he should have is prevented by eyestrain.

This then, gentlemen, is the first matter for you to discuss. Do you agree with my statement that all errors of refraction, even the smallest, should be corrected if symptoms are present? When I refer to small errors, I imply that small errors of anisometropia are as important as small errors of astigmatism. Do you agree to this?

It will be interesting to hear from those of you who have been treating "war neurasthenics" what your experience has been.

The next question is: What symptoms are we to look for ?

Every physician now knows that he should not attempt to treat a headache before eliminating the influence of the eyes; but if a headache, why not any other form of reflex irritation or nerve waste?

Only a few realize the countless functional disorders that owe their existence entirely, or mainly, to eyestrain. Such up-to-date men, when they see a patient where no organic lesion can be discovered, insist upon a careful examination of the eyes, and a correction of the error when discovered, and if eyestrain is not the sole cause of the trouble, it often is a chief cause, and when removed enables the further treatment to be successful.

Will you tell us your experience with reference to the importance from the eyestrain point of view of large errors and small errors. My experience has been that large errors " take care of themselves," as it were, the patient seeking the oculist, or perhaps the optician, because of faulty vision, and not seeking the physician because of 
some obscure symptom. I do not think that a large error imperfectly corrected (thus leaving a small amount for the patient himself to correct), is worse than no correction at all. I do not think a large error uncorrected is so productive of symptoms of eyestrain as a small error, but others may differ from this opinion.

I expect we shall all agree that it is more important to correct an error when hypermetropia is present than in the case of myopia. This was pointed out by Donders sixty years ago!

In answering this question we must not forget that small errors are much more numerous than large errors.

Recently on tabulating the results of 500 consecutive refractions giving 1,000 eyes, I found :-

866 eyes had astigmatism, of these :-

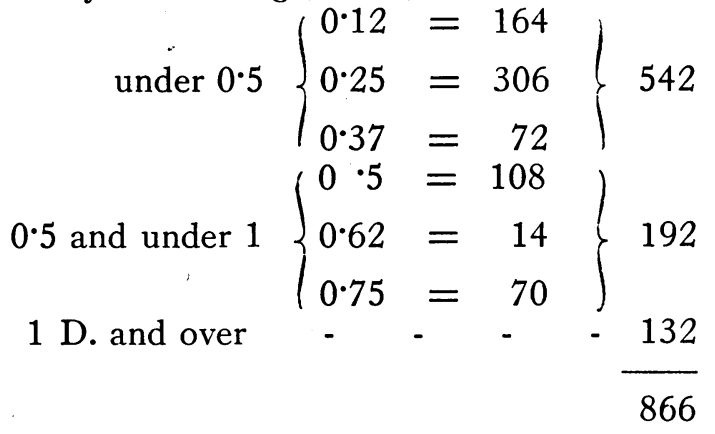

\section{2.-Treatment.}

Correct treatment can only be given if a correct diagnosis is made :-

Cycloplegics.-A discussion on this important subject ought to yield valuable material.

We have not, I consider, a satisfactory cycloplegic. We should like one that is not a mydriatic, that is thoroughly efficient, i.e., a perfect paralyser of the ciliary muscle, and one the effects of which soon disappear.

The inconvenience of atropin is so great that it is impossible to employ it, generally, for adults. Homatropin is the best substitute if used in a definite dose, such as Burroughs, Wellcome and Co.'s tabloid "W" ( $\frac{1}{50}$ grain each of hydrochlor. of cocain and homatropin). I find it quite efficient when the ciliary muscle is not too powerful, as in myopia; but in high hypermetropia, when the muscle is often hypertrophied, it is very often insufficient, and yet, these are the very cases where we dare not use atropin in older patients, even if the patient could put up with the inconvenience. My plan has been to use atropin up to 20 years, and homatropin between 20 and 40 years. But one has often to depart from this rule, using homatropin, say, for a schoolboy of 18 , up for the day, 
and using atropin for patients of 24 or 25 when the error is apparently very small and the ciliary muscle very powerful.

We may hear from some here who have successfully experimented with some other and better cycloplegic. My experience has been that with the exception of atropin and homatropin, most of the mydriatics are poor cycloplegics. Some have gone so far as to say that cycloplegics are rarely necessary in adult life. Personally, I have found that there are a few patients where the cycloplegic does not reveal anything new, but the large majority do ; and I feel that it is better to put a few to inconvenience rather than make a wrong diagnosis in the many. I invite your remarks on this all-important subject.

Instruments for measuring astigmatism.-Called by various names, ophthalmometer, astigmometer, and keratometer, they are many in number, and although I have experimented with most, the only one I have found reliable is the one I use at present, viz., the latest model of Meyrowitz's ophthalmometer. Once the individual characteristics of this instrument and the proper working have been mastered, it certainly is wonderfully accurate. I find now at the most 2 per cent. (in the last 1,000 refractions I tabulated I found the ophthalmometer tallied with the clinical examination in 982), of cases where the answers of the patient do not tally, and the presence of a sufficient amount of irregular astigmatism. is probably the cause. A very small amount of irregular astigmatism, which is often present, does not interfere. This instrument registers as small an amount as 0.12 of astigmatism and even $5^{\circ}$ of obliquity. As a time saver it is invaluable, and in giving confidence to the examiner when working out small errors, it is, to my mind, irreplaceable, and I shall be glad to hear if others can speak as highly of it, because, if so, I am sure that many of you will seek to possess this instrument if you do not do so now.

I think you will agree with me that all aids in refraction work, useful as they are in saving time and giving confidence, must be regarded as servants, and the examination of the patient before the test types must have the last word, especially when the patient's accommodation is paralyzed.

I have not referred to the value of retinoscopy because I suppose we all agree and invariably employ it; but in estimating low errors it is not delicate enough, and this is where the ophthalmometer comes in.

Having ascertained the exact correction of the error the final point is how you are going to treat it : Do you insist upon a postcycloplegic examination? Personally, I do, if I have not ascertained at the first examination what the patient will accept. It is no good giving a glass that causes worse vision than is obtained without a glass! If there is, say, $4 \mathrm{D}$. of hypermetropia in a child 
and you, as a rule, take off $1 \mathrm{D}$. for the atropin, this may be too little, and to get as distinct vision as the child had before the atropin, it may be necessary to deduct $2 \mathrm{D}$. at first.

I trust you agree with me that at the post-cycloplegic examination no alteration should be made in the cylinder?

Do you agree that in myopia the full correction should be given, and no deduction made for near work in the young? Personally, I believe it to be the only reasonable treatment. By correcting the error fully we make the patient virtually normal and thus insist upon the ciliary muscle doing its proper work. I believe this treatment to be the best preventive of progressive myopia.

In very high myopia, in oldish patients, I do not believe in giving the full correction for constant use, as it is, as a rule, intolerablebut others may have had a different experience. In such cases the best treatment is to give glasses for general use about $3 \mathrm{D}$. weaker than the full correction, and to give this -3 in the form of a "spy glass" to be used in front of the glasses when wishing to see acutely at a distance.

I may mention that in ordering glasses for myopia, I have found the patient obtained great benefit from Crookes's " $A$ " glass. This glass, of course, is specially beneficial in all refractions where the glare of light is felt.

With presbyopic patients who show astigmatism, do they tolerate the correction of it if it has never before been corrected? Personally, I consider they mostly do tolerate it, especially if given in the form of bifocals for constant use.

One word as to bifocals. Personally, I find that, if properly made, they are, in a large majority of patients, invaluable, but if they do not fit accurately they are worse than useless, and my experience is that few opticians are successful in making them. Another point to remember is, not to have the reading portion too strong. It will be interesting to learn from those of you who have experienced the work of provincial opticians, what the results have been.

Lastly, when do you order the glasses to be worn? Of course, theoretically, if you believe the error needs correcting, it should be corrected all the waking hours, and, I think, the majority of you will agree that in the case of children this should be insisted upon, except, of course, when playing games, such as football. Older patients, especially ladies, I find, emphatically decline to adopt this treatment unless they are convinced by firm and delicate arguments; but even the personality of the doctor sometimes fails here, and we have to be content with the use of glasses for near work only, allowing lorgnettes to be used for the theatre, etc.

In prescribing for presbyopia we should always ascertain the accommodative power of the individual and adapt our glass accordingly. 
I suppose we all agree that a monocle should only be allowed if one eye is blind, or partially so.

As the discussion is limited to the errors of refraction, I do not propose to refer to heterophoria except to say that my experience has been, when the error was properly corrected, the heterophoria, if small in amount, tends to disappear.

And one last word as to treatment. I am certain that the refraction of the eye is constantly changing, that is, from year to year, even in older patients - and that a fresh examination should constantly be made. My experience is that in young patients the error tends to disappear if properly corrected. On the other hand, I have noticed that as life advances, astigmatism, previously absent, sometimes appears, or tends to increase. Perhaps you will tell us your experience on this head.

I feel sure also we should never do our work on a stereotyped plan-the personal element enters so largely into every medical case. Experience teaches us that what may be a perfect treatment for one, is useless for another. One thing I am sure of, and that is, that we have reached nearer an exact science in refraction work than in any other department of medicine, and that, if we do this work conscientiously and carefully, we are more likely to benefit the human race than by tons of physic!

Well, gentlemen, with my colleague, Col. Elliot, I have tried to indicate the various ways in which you can acquaint us with your experiences. There are many points which the exigencies of time do not allow me to enumerate, but which some of you will probably tackle; and I feel sure that our united knowledge and experience will certainly help those who come after us.

\section{THREE MAGNET CASES WITH SOME UNUSUAL FEATURES}

BY

IVOR Ll. TUCKETT, M.D.Cantab.

THE following three cases were admitted to the Royal London Ophthalmic Hospital, while I was house-surgeon there in 1916-17, under the care respectively of $\mathrm{Mr}$. E. Treacher Collins and Mr. P. Flemming. They have been kind enough to give me permission to record the following facts, which I think may be of some interest to ophthalmic surgeons.

Case 1.-F. S. was admitted on November 8, 1916, with the history that the same afternoon he was hitting a piece of steel with a hammer when something flew into his right eye. On admission, 